\title{
Identification of Novel Plasmid Replicons Harboring $\beta$-Lactamase Resistant Genes in Ampicillin-Resistant Uropathogenic Escherichia coli
}

\author{
Mohamed Nawaz ${ }^{*}$, Ashraf Khan ${ }^{1}$, Saeed Khan ${ }^{1}$, Bernard Marasa ${ }^{2}$, Kiet Nguyen $^{2}$, Samia Nawaz $^{3}$ and \\ Harry Mobley ${ }^{4}$ \\ ${ }^{1}$ Division of Microbiology, National Center for Toxicological Research, US Food and Drug Administration, Jefferson, AR 72079.
}

${ }^{2}$ Center for Drug Evaluation and Research, US Food and Drug Administration, Silver Spring, MD 20903.

${ }^{3}$ Hendrix Colllege, Conway, AR 72032.

${ }^{4}$ Department of Microbiology, University of Michigan, Ann Arbor, MI 48109.

Received: 27 September, 2018; Accepted: 7 February, 2019 ; Published: 13 February, 2019

*Corresponding author: Mohamed Nawaz, Division of Microbiology, National Center for Toxicological Research, US Food and Drug Administration, Jefferson, AR 72079, USA. Tel: 8705437586 E-mail: mohamed.nawaz@fda.hhs.gov

\begin{abstract}
Misuse of $\beta$-lactam antibiotics in the treatment of urinary tract infections (UTI) may result in the prevalence of $\beta$-lactam resistant uropathogenic Escherichia coli (UPEC). This study was undertaken to study the prevalence of $\beta$-lactam resistant determinants in ninety-one uropathogenic Escherichia coli strains were isolated from patients with UTI. Twenty-four of the ninety-one isolates were resistant to multiple antibiotics. All twentyfour isolates were resistant to the $\beta$-lactam antibiotics such as penicillin and ampicillin and a majority $(16 / 24,67.0 \%)$ of the isolates had a minimum inhibitory concentration (MIC) of $256 \mu \mathrm{g} / \mathrm{mL}$ for both antibiotics. The oligonucleotide primers specific for $b a_{\text {tem }}$ and bla $_{c t x}-\mathrm{m}_{\text {amplified the }} 851$-bp and 550 -bp regions of the genes from the template DNA of $100 \%$ and $75 \%$ of the isolates, respectively. PCR results also indicated that $75 \%$ of the isolates contained both genes. High MIC values $(256 \mu \mathrm{g} / \mathrm{mL})$ were observed in isolates simultaneously harboring both genes compared to isolates containing just one $\beta$-lactam resistance determinant. Twenty one of the 24 isolates contained plasmids measuring 2.5 to $16.0 \mathrm{~kb}$ and 12 of the 21 strains harbored mega plasmids (above $16.0 \mathrm{~kb}$ ). PCR based replicon typing (PBRT) was used to screen the template DNA from 24 of these isolates for the presence of 15 major plasmid families. Oligonucleotide primers specific for the detection of I1 plasmid amplified the replicon in 17 of 21 (81.0\%) of the isolates. Similarly, PCR protocols specific for the detection of B/O and FIA plasmids detected these plasmids in $46.0 \%$ and $75.0 \%$ of the isolates. The $\beta$-lactam resistance determinants were successfully transferred to Salmonella $s p$. by conjugation along with I1 and B/0 plasmid families but the conjugation protocol failed to transfer the FIC plasmid. Pulsed field gel electrophoresis (PFGE) indicated 16 different XbaI digested macrorestriction profiles (mrps) among the 24 UPECs. Our results indicate that the use of $\beta$-lactams in clinical practice may select for UPECs resistant to these drugs.
\end{abstract}

Keywords: Beta Lactam resistance; Plasmid Replicons; Uropathogenic E. coli.

\section{Introduction}

Urinary tract infection (UTI) is a chronic, recurrent bacterial infection of the urogenitals $[1,2]$. It may involve the lower urinary tract or the lower and upper urinary tracts combined. Infections of the urethra or the bladder can cause painful, frequent urination, cloudy, foul-smelling urine, and mild abdominal pain. Currently, more than a billion women suffer from UTI worldwide. UTI affects approximately 8 million American women every year resulting in approximately 100,000 hospitalizations [2]. It is a common cause of hospitalization in elderly women who suffer from renal insufficiency, diabetes or immunodeficiency; or have undergone organ transplantation. Postmenopausal women also have higher rates of UTI if they have pelvic prolapse, lack of estrogen or diabetes. Untreated UTI contributes to preterm labor, reduced kidney function or failure, agitation, delirium, and behavior instability in the elderly [3]. Complicated UTI is usually present in patients having functional or structural abnormalities or having had urinary instrumentation or other complications, such as diabetes or organ transplantations. The incidence of UTI increases with age and sexual activity $[3,4]$.

A majority (80\%) of community-acquired uncomplicated UTI are caused by uropathogenic Escherichia coli (UPEC) [2]. Antibiotics are widely used in the treatment of UTI [1]. However, the widespread use of antibiotics has led to the occurrence of multiple antibiotic-resistant UPEC [4]. Resistance to ampicillin and other $\beta$-lactam antibiotics is mediated by $\beta$-lactamase-producing UPEC [5-8]. Several cases of UTI caused by $\beta$-lactamases and extended-spectrum $\beta$-lactamases (ESBL) producing UPEC have been documented worldwide [4, 9] and plasmids are known to play a vital role in the transmission of 
ESBL genes [9-11]. However, there is a paucity of information on the types of plasmid replicon harboring $\beta$-lactamase resistance determinants in clinical ecosystems. Such information is needed for understanding the epidemiological dynamics and to devise interventional strategies to limit the spread of specific plasmid replicons to other ecosystems. The characterization of plasmids and antimicrobial sensitivity profiles will be extremely useful for epidemiologists in tracking the spread of antibiotic resistant uropathogenic E. coli within and between ecosystems and in prescribing the appropriate antibiotic therapy for the efficient management of UTI. In this report, we describe the antibiotic resistance profiles and the genetic characteristics of 24 ampicillin-resistant UPEC isolated from patients suffering from the infection.

\section{Materials and Methods}

\section{Collection of Uropathogenic $E$. coli}

Ninety-one uropathogenic E. coli (UPEC) strains were obtained from the Department of Microbiology and Immunology of the University of Michigan, Ann Arbor, MI. All isolates were stored in Luria-Bertani (LB) broth containing $20 \%$ glycerol at $-70^{\circ} \mathrm{C}$ and were grown overnight at $37^{\circ} \mathrm{C}$ in $\mathrm{LB}$ or on trypticase soy agar (TSA) plates supplemented with 5\% sheep blood (Thermo Fisher Scientific).

Determination of Antibiotic Susceptibility and the Minimum Inhibitory Concentration (MIC) of the Isolates

The antibiotic susceptibility of each isolate was determined by a disc diffusion assay [12]. The susceptibility of each isolate was determined as per the criteria specified by the Clinical and Laboratory Standards Institute (CLSI 2002). MICs for ampicillin and penicillin ( $\beta$-lactam antibiotics) were determined by the broth dilution method using Mueller-Hinton broth (Oxoid Ltd., Basingstoke, UK).

\section{Genomic DNA Extraction}

Genomic DNA was extracted from cells grown overnight at $37^{\circ} \mathrm{C}$ using a QIAamp DNA Mini Prep Kit (QIAGEN, Valencia, CA).

\section{Detection of $\beta$-Lactamase Genes from Template DNA}

The presence of the various $\beta$-lactam resistance genes (oxa, pse, shv, tem, ctx-m, ctx-m-9, cmy, fox, imp, kpc, vim) in the template DNA was investigated by PCR with the primers used for the amplification of these genes listed in (Table 1) [13].

Table 1: Oligonucleotide primers used in the amplification of $\beta$-lactam resistance genes from uropathogenic Escherichia coli strains.

\begin{tabular}{|c|c|c|c|}
\hline Primers & Nucleotide Sequence & Target gene & Size (bp) \\
\hline blaOXAF & GCAGCGCCAGTGCATCAAC & $O X A-1$ & 198 \\
\hline blaOXAR & CCGCATCAAATGCCATAAGTG & & \\
\hline blaPSEF & AGTAGGGCAGGCAATCACAC & $P S E-1$ & 421 \\
\hline blaPSER & GCGATCCGCAATGTTCCATC & & \\
\hline blaSHVR & GGTTAGCGTTGCCAGTGCT & & \\
\hline blaTEMF & ATGAGTATTCAACATTTCCG & $T E M$ & 851 \\
\hline blaTEMR & TTAATCAGTGAGGCACCTAT & & \\
\hline blaCTXMF & CGCTTTGCGATGTGCAG & CTX-M & 550 \\
\hline blaCTXMR & ACCGCGATATCGTTGGT & & \\
\hline blaCTXM9F & GTGACAAAGAGAGTGCAACGG & СТХМ9 & 856 \\
\hline blaCTXM9R & ATGATTCTCGCCGCTGAAGCC & & \\
\hline blaCMYF & TGGCCAGAACTGACAGGCAAA & $C M Y 2$ & 462 \\
\hline blaCMYR & TTTCTCCTGAACGTGGCTGGC & & \\
\hline blaFOXF & AACATGGGGTATCAGGGAGATG & FOX & 190 \\
\hline blaFOXR & CAAAGCGCGTAACCGGATTGG & & \\
\hline blaIMPF & CATGGTTTGGTGGTTCTTGT & $I M P$ & 447 \\
\hline blaIMPR & ATAATTTGGCGGACTTTGGC & & \\
\hline blaKPCF & CAGCTCATTCAAGGGCTTTC & $K P C$ & 533 \\
\hline blaKPCR & AGTCATTTGCCGTGCCATAC & & \\
\hline blaVIMF & AGTGGTGAGTATCCGACAG & $V I M$ & 261 \\
\hline
\end{tabular}




\section{Isolation of Plasmids}

Plasmid DNA was isolated using a modified alkaline lysis method $[14,15]$. Samples were analyzed by electrophoresis in 1 $\mathrm{X}$ Tris acetate-EDTA buffer at $64 \mathrm{~V}$ for $2 \mathrm{~h}$ on $1.0 \%$ agarose gels. A supercoiled DNA Ladder (Invitrogen, Carlsbad, CA) was used as a molecular weight marker.

\section{Plasmid Typing}

Plasmids were typed by the PCR-based replicon typing (PBRT) method with primers listed in (Table 2) [16].

Table 2: Oligonucleotide primers used in the replicon typing of the plasmids isolated from the uropathogenic E. coli.

\begin{tabular}{|c|c|c|c|}
\hline Primers & Nucleotide Sequence & Target gene & Size (bp) \\
\hline $\mathrm{A} / \mathrm{CF}$ & GAGAACCAAAGACAAAGACCTGGA & repA & 465 \\
\hline $\mathrm{A} / \mathrm{CR}$ & ACGACAAACCTGAATTGCCTCCTT & & \\
\hline $\mathrm{B} / \mathrm{OF}$ & GCGGTCCGGAAAGCCAGAAAAC & $R N A i$ & 159 \\
\hline $\mathrm{B} / \mathrm{OR}$ & TCTGCGTTCCGCCAAGTTCGA & & \\
\hline FIAF & CCATGCTGGTTCTAGAGAAGGTG & iterons & 462 \\
\hline FIAR & GTATATCCTTACTGGCTTCCGCAG & & \\
\hline FICF & GTGAACTGGCAGATGAGGAAGG & repA2 & 262 \\
\hline FICR & TTCTCCTCGTCGCCAAACTAGAT & & \\
\hline FIIA/FIISF & CTGTCGTAAGCTGATGGC & repA & 270 \\
\hline FIIA/FIISR & CTCTGCCACAAACTTCAGC & & \\
\hline FIBR & CTCCCGTCGCTTCAGGGCATT & & \\
\hline HI1F & GGAGCGATGGATTACTTCAGTAC & parA-parB & 471 \\
\hline HI1R & TGCCGTTTCACCTCGTGAGTA & & \\
\hline $\mathrm{HI} 2 \mathrm{~F}$ & TTTCTCCTGAGTCACCTGTTAACAC & iterons & 644 \\
\hline $\mathrm{HI} 2 \mathrm{R}$ & GGCTCACTACCGTTGTCATCCT & & \\
\hline $\mathrm{I} 1 \mathrm{~F}$ & CGAAAGCCGGACGGCAGAA & $R N A i$ & 139 \\
\hline I1R & TCGTCGTTCCGCCAAGTTCGT & & \\
\hline $\mathrm{K} / \mathrm{BF}$ & GCGGTCCGGAAAGCCAGAAAAC & $R N A i$ & 160 \\
\hline $\mathrm{K} / \mathrm{BR}$ & TCTTTCACGAGCCCGCCAAA & & \\
\hline $\mathrm{L} / \mathrm{MF}$ & GGATGAAAACTATCAGCATCTGAAG & repA,B,C & 785 \\
\hline $\mathrm{L} / \mathrm{MR}$ & CTGCAGGGGCGATTCTTTAGG & & \\
\hline NR & GTTTCAACTCTGCCAAGTTC & & \\
\hline $\mathrm{TF}$ & TTGGCCTGTTTGTGCCTAAACCAT & repA & 750 \\
\hline TR & CGTTGATTACACTTAGCTTTGGAC & & \\
\hline WF & CCTAAGAACAACAAAGCCCCCG & repA & 242 \\
\hline WR & GGTGCGCGGCATAGAACCGT & & \\
\hline $\mathrm{XF}$ & AACCTTAGAGGCTATTTAAGTTGCTGAT & oriy & 376 \\
\hline $\mathrm{XR}$ & TGAGAGTCAATTTTTATCTCATGTTTTAGC & & \\
\hline
\end{tabular}

\section{Conjugation}

Twenty-four ampicillin-resistant UPEC isolates (donors) and a tetracycline- resistant but ampicillin-sensitive Salmonella food isolate (recipient) were used for conjugation experiments to determine transferability of $\beta$-lactamase genes. The broth mating conjugation method was performed as previously described [17]. LB agar plates containing tetracycline $(15 \mu \mathrm{g} / \mathrm{mL})$ with ampicillin $(200 \mu \mathrm{g} / \mathrm{mL})$ were used to select transconjugants harboring genes conferring $\beta$-lactam antibiotic resistance.

\section{Pulsed Field Gel Electrophoresis (PFGE)}

PFGE was performed as described earlier on genomic DNA samples of the isolates [18]. DNA plugs were digested overnight with $20 \mathrm{U}$ of $\mathrm{XbaI}$ (New England Biolabs, Beverly, MA) at $37^{\circ} \mathrm{C}$. The genetic relationships among the 24 ampicillin-resistant UPEC isolates were analyzed using BioNumeric software (Applied Maths, Kortrijk, Belgium). 


\section{Results}

\section{Antibiotic resistance Profiles of Uropathogenic E. coli}

Twenty-four of the ninety one isolates were resistant to ampicillin and penicillin. Two of the isolates were resistant to ampicillin, penicillin and streptomycin. Two isolates were resistant to ampicillin, penicillin, tetracycline and doxycycline. Another two isolates were resistant to ampicillin, penicillin, tetracycline, doxycycline and streptomycin. Three isolates were resistant to a combination of antibiotics including ampicillin, penicillin, chloramphenicol, kanamycin, tetracycline, doxycyline and streptomycin. Fourteen of the 24 were resistant only to ampicillin and penicillin. Sixteen of the 24 isolates (67.0\%) had an MIC of $256 \mu \mathrm{g} / \mathrm{mL}$ for both penicillin and ampicillin. Thirty three percent of the isolates had an MIC of $2-4 \mu \mathrm{g} / \mathrm{mL}$ for ampicillin and $16-32 \mu \mathrm{g} / \mathrm{mL}$ for penicillin.

\section{PCR Amplification of $\beta$-lactam Resistance Genes}

The template DNAs from the $24 \beta$-lactam antibiotic-resistant strains were screened for the presence of 11 different $\beta$-lactam resistance genes. The oligonucleotide primers specific for the amplification of bla $a_{\text {tem }}$ amplified the 851-bp region of this gene from the template DNA of all uropathogenic E. coli (Figure 1A). The oligonucleotide primers specific for the amplification of bla $a_{\text {стхмм }}$ amplified the 550-bp region of the gene from the template DNA of 18 of the $24(75.0 \%)$ of the isolates (Figure 1B). PCR results also indicated that template DNA of these 18 isolates (75.0\%) contained both $b l a_{\text {tem }}$ and $b l a_{\text {СTX-M }}$ (Figure1C). PCR failed to amplify the other nine $\beta$-lactam resistance genes from the template DNA of any of the $24 \beta$-lactam -resistant isolates.

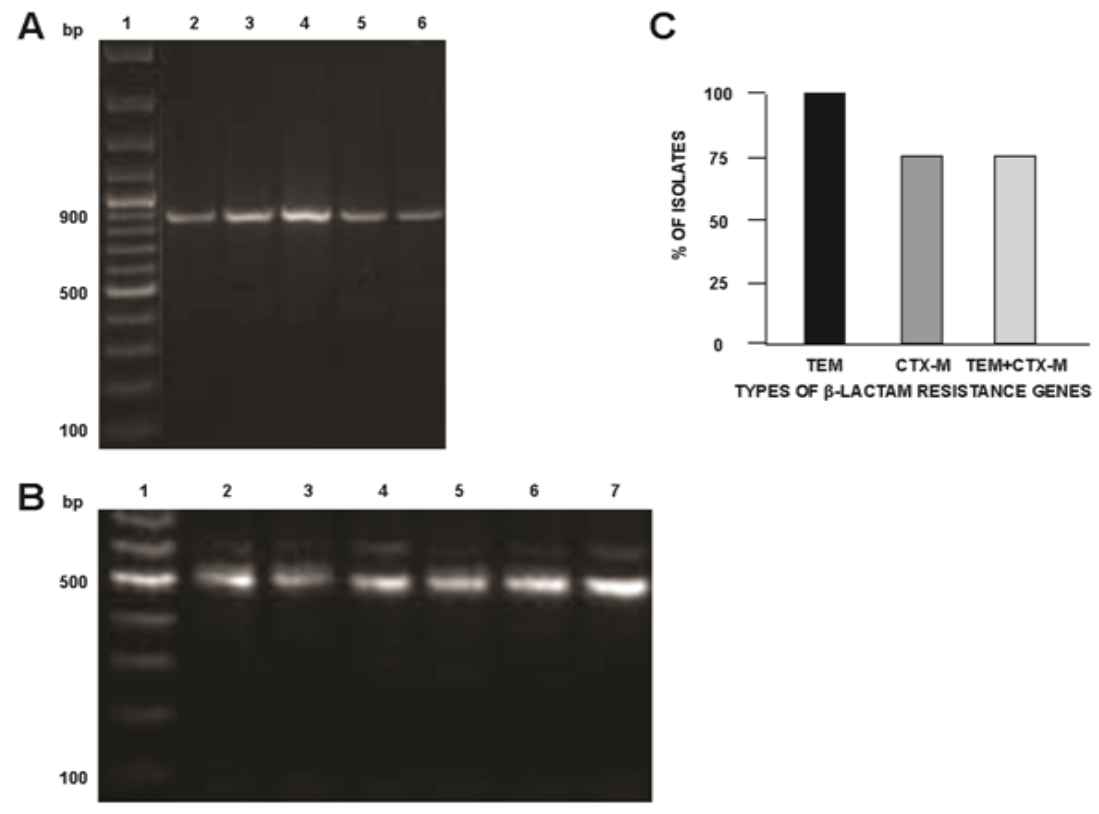

Figure 1: Detection and quantification of $\beta$-lactamase genes in the template DNA of uropathogenic E. coli by polymerase chain reaction (PCR). (A) Lane 1, 100- bp molecular weight marker; lanes 2-6, 851-bp blaTEM amplified from the template DNA. (B) Lane 1, 100-bp molecular weight marker;

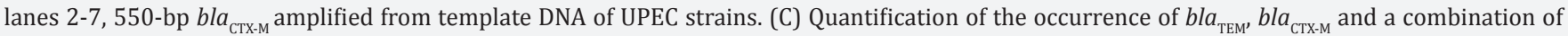
these genes in the template DNA of the UPEC isolates.

\section{Plasmid Identification and Typing by PCR}

The PCR-based replicon typing (PBRT) was used for plasmid identification, targeting the replicons of the 15 major plasmid families occurring in the template DNAs of $24 \beta$-lactam-resistant uropathogenic $E$. coli strains. The oligonucleotide primers specific for the amplification of a 159-bp region of the B/O plasmid replicon amplified a part of the plasmid from the template DNA of 11 of the $24(45.0 \%)$ strains (Figure 2A). Oligonucleotide primers specific for the identification of the FIA plasmid successfully amplified a 462-bp region of the replicon from 18 of $24(75.0 \%)$ of the isolates (Figure 2B). Similarly, oligonucleotide primers specific for the detection of I1 plasmid successfully amplified a 139-bp region of the replicon from the template DNA of 19 of the $24(79.0 \%)$ isolates (Figure 2C). The template DNA of 11 strains contained both FIA and $\mathrm{B} / 0$ replicons, as indicated by the amplification of a 462-bp region of the FIA and 159-bp region of the I1 replicon (Figure 2D). The PCR protocols also indicated that five of the 24 strains simultaneously harbored FIA, I1 and B/O replicons in their template, as indicated by the amplification of a 462-bp region of FIA, a 139-bp region of I1 and a 159-bp region of the $\mathrm{B} / \mathrm{O}$ replicon. The primers failed to amplify any of the other 12 plasmid families from the template DNA of the isolates. 
A

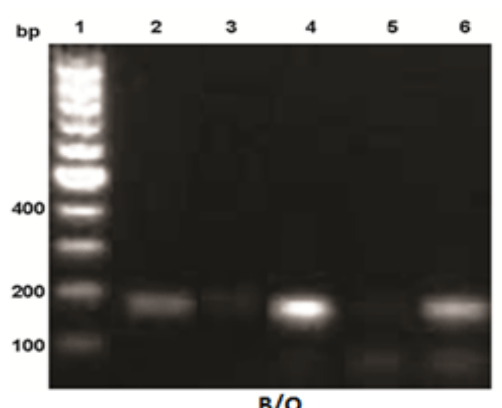

C

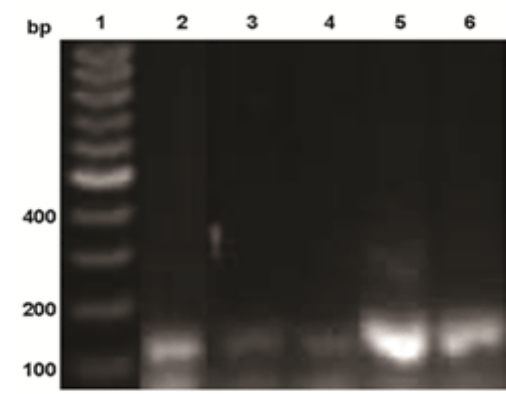

11

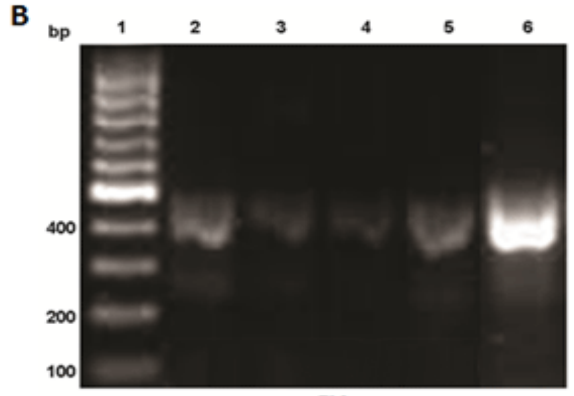

FIA

D

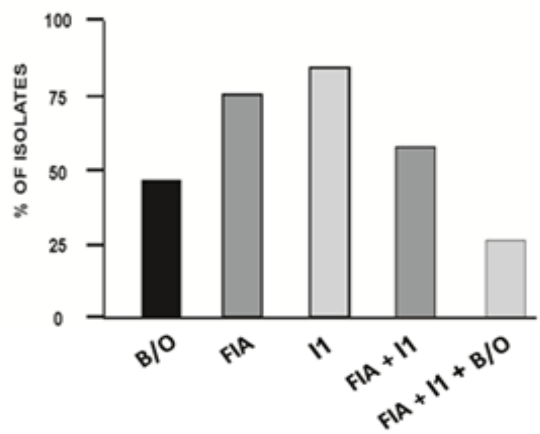

Figure 2: Detection and quantification of the various kinds of plasmid families by PCR-based replicon typing. (A) Lane 1, 100-bp molecular weight marker; lanes 2-6, 159-bp region of the B/O plasmid. (B) Lane 1, 100-bp molecular weight marker; lanes 2-6, 469-bp region of the FIA plasmid. (C) Lane 1, 100-bp molecular weight marker; lanes 2-6, 139-bp region of the TI plasmid. (D) Quantification of the occurrence of different plasmid families in the template DNA of UPEC strains.

\section{Characterization of Plasmids Isolated from Ampicillin- Resistant Uropathogenic E. coli}

Attempts were made to isolate the plasmids from all 24 ampicillin-resistant uropathogenic E. coli strains. Three of the twenty four isolates did not contain any plasmids. Twenty-one isolates contained plasmids which varied in sizes from 2.5 to greater than $16.0 \mathrm{~kb}$ ((Figure3), lanes 1-15). Strain CFT 097 (lane 1) was distinct from other strains by harboring three plasmids, two measuring 6.0 and $11.0 \mathrm{~kb}$ and a megaplasmid measuring above $16.0 \mathrm{~kb}$. Strain CFT429 (lane 2) harbored three plasmids; two small plasmids measuring 2.9 and ca. $7.0 \mathrm{~kb}$ and a megaplasmid (M1) measuring above $16.0 \mathrm{~kb}$. Similarly, strain F15 (lane 3) had three plasmids; two small plasmids measuring 6.0 and $7.0 \mathrm{~kb}$ and the megaplasmid M1 measuring above $16.0 \mathrm{~kb}$. Strain CPZ421 (lane 4) had two plasmids, a small plasmid measuring $6.0 \mathrm{~Kb}$ and the megaplasmid M1. Strains CPZ426 (lane 5), CFT 450 (lane 10), F54 (lane 11) and CFT (lane 15) also contained the megaplasmid. Strains CPZ427 (lane 6) and CPZ 542 (lane 8) had two plasmids measuring ca. 7.0 Kb and the megaplasmid. Strain CPZ (lane 7) had 4 plasmids, two measuring 2.9 and $8.0 \mathrm{~Kb}$ and two megaplasmids (M1 and M3). Strains CPZ609 had a small plasmid (ca. 7.0 kb) and the M1 plasmid. Strain CFT428 (lane 12) had a small plasmid (10 kb) and the megaplasmid M1. Similarly, strains CFT375 (lane 13) had a small plasmid $(6.0 \mathrm{kB})$ and the M1. Strain 149 (lane 14) had 2 small plasmids measuring $5.0 \mathrm{~kb}$ and a megaplasmid. Strain CFT434 (lane 15) had megaplasmid M1.

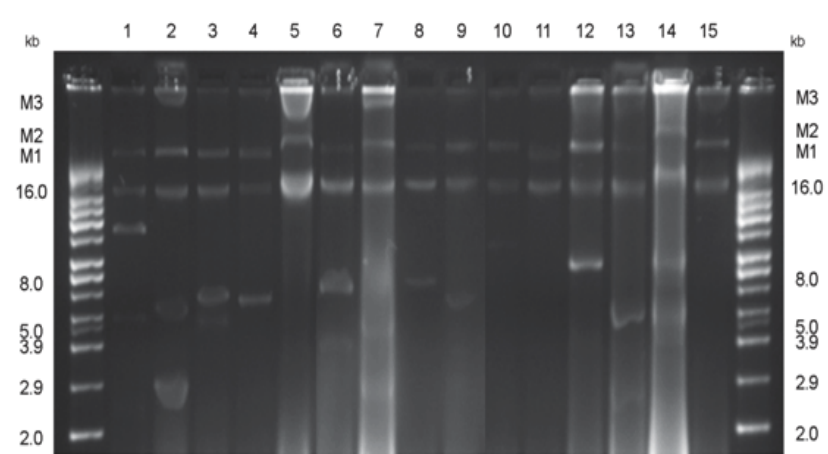

Figure 3: Profiles of plasmids isolated from UPEC strains (Lanes 1-15). Lane 1, strain CFT097, lane 2, strain CFT429, lane 3, strain F15, lane 4, strain CPZ 421, lane 5, CPZ 426, lane 6, CPZ 427, Lane 7, strain CPZ529, lane 8, strain CPZ542, lane 9, CPZ609, lane 10, CFT450, lane 11, strain 54, lane 12, CFT428, lane 13, CFT375, Lane 14, CFT149, lane 15, CFT434

\section{Horizontal Transfer of $\beta$-lactam-Resistance Phenotypes and Genotypes}

Transconjugants were only obtained with Salmonella strain 942 as recipient. No transconjugants were obtained when Salmonella strain 909 was used as a recipient. All transconjugants were resistant to ampicillin $(256 \mu \mathrm{g} / \mathrm{mL})$ and tetracycline $(15 \mu \mathrm{g} / \mathrm{mL})$. Template DNA from twenty five transconjugants was screened for the $11 \beta$-lactamase-resistance genes. The 
oligonucleotide primers specific for the amplification of bla $a_{t e m}$ amplified the 851-bp region of the gene from the template DNA of all 25 transconjugants. Similarly, the oligonucleotide primers specific for the amplification of bla $a_{\text {CTX-m }}$ amplified the 550-bp region of the gene from the template DNA of all 25 transconjugants. No other $\beta$-lactam-resistance genes were amplified from the template DNA of the transconjugants. The template DNA from the 25 transconjugants was typed using the PCR-based replicon assay (Table 2). Oligonucleotide primers specific for the amplification of the I1 plasmid replicon successfully amplified a 139-bp region of the replicon from the template DNA of 21 of the $25(84.0 \%)$ isolates. Similarly, primers specific for the amplification of the B/O plasmid replicon successfully amplified a 159-bp region of the replicon from the template DNA of $22 / 25$ isolates $(88.0 \%)$. FIA plasmid-specific primers failed to amplify the 469-bp region of the replicon from the template DNA of any of the 25 transconjugants.

\section{Pulsed Field Gel Electrophoresis (PFGE)}

All $24 \beta$-lactam resistant UPECs were typeable by the PFGE methodology used. XbaI-PFGE identified 16 distinct macrorestriction patterns (mrps) among the 24 UPEC strains (Figure 4). Dendrogram analysis indicated that the XbaIdigested profile of CFT449, which was resistant to tetracycline, doxycycline, ampicillin and penicillin, had a identical similarity index of $85.0 \%$ with the $X b a-$ I digested profile of F54, which was only resistant to ampicillin and penicillin. Similarly, the restriction profile of strain CFT450, which was resistant to five different antibiotics (tetracycline, doxycycline, ampicillin, streptomycin and penicillin), had an approximately $80 \%$ similarity index to the restriction patterns of strains CFT449 and F54. The Xba-I restriction profile of strain CFT108, which was resistant to tetracycline, doxycycline, kanamycin, streptomycin, ampicillin and penicillin had a $67.0 \%$ similarity index with strain F5, which was resistant to tetracycline, doxycycline, ampicillin, streptomycin and penicillin and strain CFT097 which was resistant to streptomycin and penicillin. The restriction profiles of other strains had a similarity index of less than $65.0 \%$.

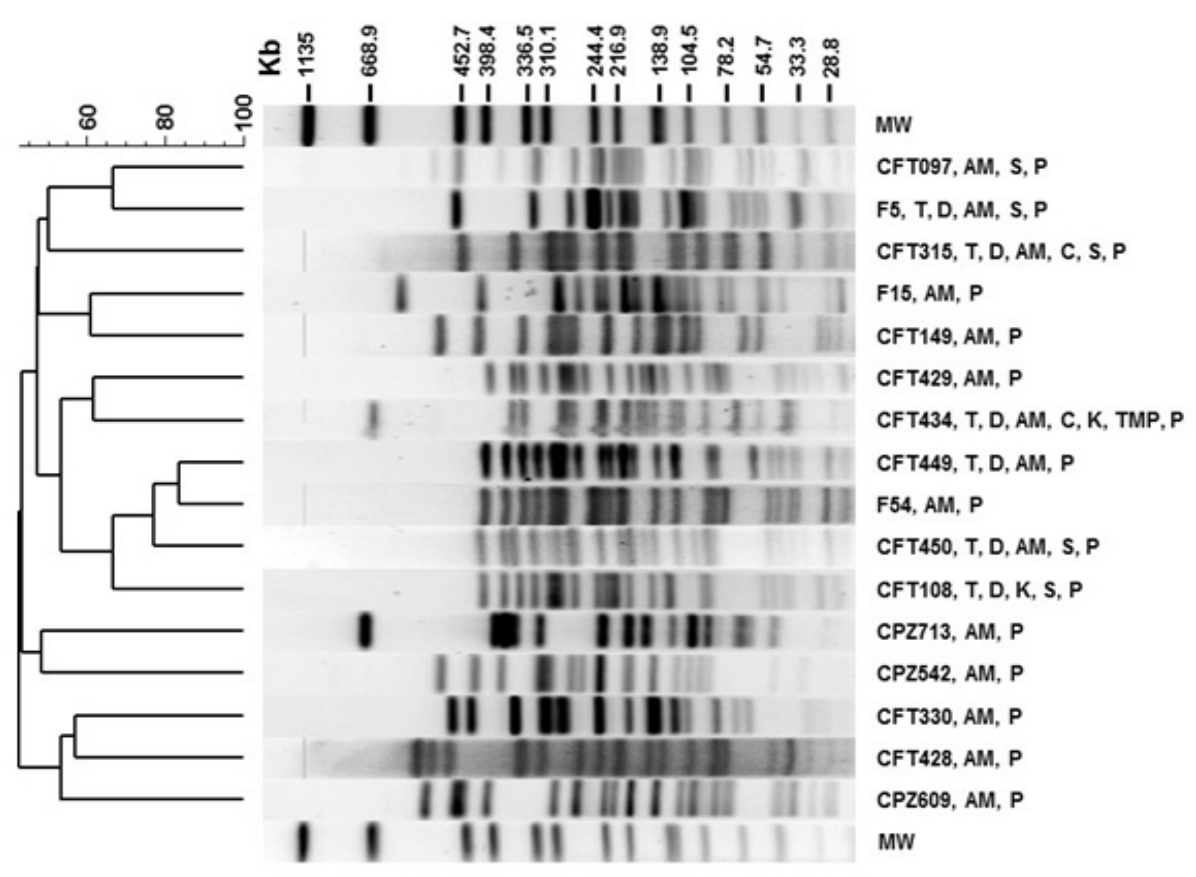

Figure 4: XbaI pulsed field gel electrophoresis (PFGE) of the genomic DNA of uropathogenic strains and a dendrogram analysis of the macrorestriction patterns by the Bionumeric software. Strains were resistant to the following antibiotics: AM, ampicillin; P, penicillin; T, tetracycline, D, doxycycline, C, chloramphenicol, K, kanamycin, S, streptomycin; TMP, trimethoprim

\section{Discussion}

Extended spectrum $\beta$-lactamases (ESBLs) are enzymes conferring broad resistance to $\beta$-lactam antibiotics. More than 300 variants of ESBLs have been described to date in numerous species of Gram-negative bacteria [5, 7, and 19]. A majority of ESBLs belong to the TEM and SHV families $[7,19]$. The ESBL genes are usually plasmid-mediated and their gene products are known to hydrolyze and inactivate a wide variety of $\beta$-lactams, such as third-generation cephalosporins, penicillins, ampicillins and aztreonams. Indeed, these two resistance determinants are widely prevalent in most ESBL-resistant $E$. coli and K. pneumoniae and to a lesser extent on other genera of Enterobacteriaceae [5, 7, and 19]. These studies also indicate that $b a_{\text {tem }}$ is responsible for up to $90.0 \%$ of ampicillin and penicillin resistance. The molecular screening for 11 different $\beta$-lactam resistance genes in the 
template DNA of the 24 multiple antibiotic-resistant isolates in this study indicates the presence of bla ${ }_{\text {tem }}$ in the template DNA of all isolates. However, blashv was absent. Our results also indicate that the template DNA from $84.0 \%$ of the isolates in this study harbored the $b l a_{\text {CTX-m }}$ gene. CTX-M type ESBLs are a new family of plasmid mediated ESBLs originally reported in Salmonella [20, 21]. CTX-M $\beta$-lactamases constitute a rapidly growing family with six groups and more than 50 allotypes [7, 19]. Recently, CTX-M phentotypes have also been reported in E. coli strains isolated from healthy humans, livestock, companion animals, food products, and sewage, indicating the magnitude of the reservoirs harboring and disseminating these ESBLs $[20,21]$.

We correlated the MIC values for penicillin and ampicillin in each UPEC isolate in this study with the occurrence of bla $a_{t e m}$ and $b l a_{\text {стX-m }}$ in these isolates (Table 3). Our data indicate that thirtythree percent of the isolates had an MIC of $16-32 \mu \mathrm{g} / \mathrm{mL}$ for penicillin and 2-4 $\mu \mathrm{g} / \mathrm{mL}$ for ampicillin. PCR data on the presence of $b l a_{\text {tem }}$ or $b l a_{\text {CTX-m }}$ in these isolates indicated the presence of either one of the genes in the template DNA of these isolates. None of these isolates were found to simultaneously harbor both genes. However, $66.0 \%$ of the UPEC strains examined in this study had an MIC of $256 \mu \mathrm{g} / \mathrm{mL}$ for both ampicillin and penicillin. These isolates harbored $b l a_{\text {tem }}$ and $b l a_{\text {стх-m }}$ simultaneously. It is possible that simultaneous occurrence of two or more ESBL genes may be necessary for higher MIC values in these isolates.

Table 3: Relationship of the Minimum inhibitory concentration (MIC) to the presence of $\beta$-lactamase genes.

\begin{tabular}{|c|c|c|c|c|}
\hline \multirow{2}{*}{$\begin{array}{c}\text { No. of } \boldsymbol{E} \text {. coli } \\
\text { strains }\end{array}$} & \multicolumn{2}{|c|}{$\mathbf{M I C}(\boldsymbol{\mu g} / \mathbf{m L})$} & \multicolumn{2}{c|}{ Presence/Absence of } \\
\cline { 2 - 5 } & $\mathbf{A m p}$ & $\mathbf{P C N}$ & $\boldsymbol{b l a}_{\text {TEM }}$ & $\boldsymbol{b l a}_{\text {cTX-M }}$ \\
\hline 2 & 2 & 16 & + & - \\
\hline 2 & 3 & 16 & + & - \\
\hline 2 & 3 & 24 & + & - \\
\hline 1 & 4 & 24 & + & - \\
\hline 1 & 4 & 32 & + & - \\
\hline 16 & 256 & 256 & + & + \\
\hline
\end{tabular}

The majority of UPEC strains in this study harbored plasmids of different sizes and from different plasmid families, as determined by PBRT. Johnson et al analyzed over 200 UPEC strains and indicated that plasmid replicon type Frep was the most prevalent plasmid type occurring in more than $73 \%$ of the UPEC strains followed by FIB (56. 0)\%, B/O (24.0\%), I1 and FIA were present in 6.6 and $1.5 \%$ of the isolates, respectively [19]. However, the function of none of these plasmid replicons in these strains were not determined. Results from our investigation indicate that I1 is the dominant plasmid replicon found to occur in $79.0 \%$ of the strains, followed by FIA in $75.0 \%$ of the isolates respectively. Our investigation also documented that I1 and $\mathrm{B} / 0$ plasmid replicons harbor the $\beta$-lactam resistance and they were transferable to sensitive enteric strains of Salmonella by conjugation. Our investigation may be the first of its kind to document that these two plasmid replicons may be carriers of $\beta$-lactam resistant genes in UPEC strains.
The $24 \beta$-lactam resistant UPECs can be divided into six different groups based on their antibiotic resistance profiles, 21 different groups based on plasmid profiles, and 16 distinct profiles based on the PFGE mrps. These results indicate that the spread of $\beta$-lactam resistant UPECs in these clinical ecosystems was not due to the prevalence of a single clone. It is possible that horizontal transfer of plasmids containing $b l a_{T E M}$ and $b l a_{\text {CTX-M }}$ may play a vital role in the spread of these resistance determinants in clinical ecosystems.

The occurrence and prevalence of multidrug resistant UPECs is a huge burden for millions of people and the healthcare system [6]. Additionally, the prevalence and treatment of ESBL UPEC could add to the financial burden for millions of individuals and present a major challenge to the clinical management of UTI. The development and spread of ESBLs in the clinical environment is probably due to the misuse of $\beta$-lactams in healthcare facilities, due to the horizontal transmission of these genes among enteric bacteria $[11,22]$. Furthermore, the dissemination of plasmids harboring these resistance genes may become a public health issue [8, 23 and 24]. Thus the ability to monitor and screen plasmids and their resistance determinants by molecular methods may be helpful in furthering our knowledge of the horizontal dissemination of these molecular determinants and the spread of antibiotic resistance genes. Lastly, prudent use of antibiotics and better understanding of the underlying molecular mechanisms of resistance should limit their prevalence.

\section{Funding}

This work was supported by the National Center for Toxicological Research, US Food and Drug Administration (FDA); the views presented here do not necessarily reflect those of the USFDA.

\section{Competing Interests}

None declared

\section{Ethical Approval}

Not required.

\section{References}

1. Barber AE, Norton JP, Spivak AM and Mulvey MA. Urinary tract infection: current and emerging management strategies. Clin Infect Dis. 2013; 57(5): 719-724. Doi: 10.1093/cid/cit284.

2. Foxman B. Epidemiology of urinary tract infections: incidence, morbidity and economic costs. Am JMed. 2002; 113.

3. Dielubanza EJ and Schaeffer AJ. Urinary tract infections in women. Med Clin North Am. 2011; 95(1): 27-41. Doi: 10.1016/j.mcna.2010.08.023.

4. Blango MG and Mulvey MA. Persistence of uropathogenic Escherichia coli in the face of multiple antibiotics. Antimicrobial Agents and Chemotherapy. 2010; 54(5): 1855-1863. Doi:10.1128/AAC.00014-10.

5. Bajaj P, Singh NS and Virdi JS. Escherichia coli $\beta$-lactamases: what really matters. Front. Microbiol. 2016; 7: 417 Doi: 10.3389/ fmicb.2016.00417.

6. Brown P, Ki M and Foxman B. Acute pyelonephritis among adults: cost of illness and considerations for the economic evaluation of therapy. 
Pharmacoeconomics 2005; 23(11): 1123-42. DOI:10.2165/00019053200523110-00005

7. Nathisuwan S, Burgess DS and Lewis JS. Extended-spectrum beta lactamases: epidemiology, detection, and treatment. Pharmacotherapy 2001; 21(8): 920-928.

8. Sturenburg E and Mack D. Extended-spectrum beta-lactamases: implications for the clinical microbiology, laboratory, therapy, and infection control. J Infect. 2003; 47(4): 273-295.

9. Bush K. Alarming $\beta$-lactamase-mediated resistance in multidrug resistant Enterobacteriaceae. Curr Opin Microbiol. 2010;13(5):558564. Doi: 10.1016/j.mib.2010.09.006.

10. Carattoli A. Plasmids and spread of resistance. Int. J. Med. Microbiol 2013; 303(6-7): 298-304. Doi: 10.1016/j.ijmm.2013;02.001.

11. Johnson TJ, Wannemuehler YM, Johnson SJ, Logue CM, White DC, Doekott C, etal. Plasmid replicon typing of commensal and pathogenic Escherichia coli isolates. Appl Environ Microbiol. 2007; 73(6): 19761983. Doi:10.1128/AEM.02171-06.

12. Bauer AW, Kirby WM, Sherris JC and Turck M. Antibiotic susceptibility testing by a standardized single disk method. Am J Clin Pathol. 1966; 45(4): 493-496.

13. Bae D, Cheng CM and Khan AA. Characterization of extended-spectrum $\beta$-lactamase (ESBL) producing non-typhoidal Salmonella (NTS) from imported products. Int. J. Food Microbiol. 2015; 214: 12-17. Doi:10.1016/j.ijfoodmicro.2015.07.017.

14. Ponce E, Khan AA, Cheng CM, Summage-West C and Cerniglia CE. Prevalence and characterization of Salmonella enterica serovar Weltevreden from imported seafood. Food Microbiol. 2008; 25(1): 29 35 .Doi:10.1016/j.fm.2007.09.001.

15. Sambrook J, Fritsch EF and Maniatis T. Molecular Cloning. A Laboratory Manual. Second ed. Cold Spring Harbor Laboratory Press, New York, USA.

16. Carattoli A, Bertini A, Villa L, Falbo V, Hopkins KL and Threlfall EJ. Identification of plasmids by PCR-based replicon typing. J MicrobiolMethods. 2005; 63(3): 219-228. DOI:10.1016/j. mimet.2005.03.018.
17. Tran QT, Nawaz MS, Deck J, Nguyen KT and Cerniglia CE. Plasmidmediated quinolone resistance in Pseudomonas putida isolates from imported shrimp. Appl Environ Microbiol. 2011; 77(5)1885-1887. Doi: 10.1128/AEM.01176-10

18. Tenover FC, Arbeit RD, Goering RV, Mickelsen PA, Murray BE, Persing $\mathrm{DH}$, etal. Interpreting chromosomal DNA restriction patterns produced by pulsed field gel electrophoresis: criteria for bacterial strain typing. J Clin Microbiol. 1995 ;33(9):2233-2239.

19. Leonard DA, Bonomo RA and Powers RA. Class D $\beta$-lactamases: A re-appraisal after five decades. Acc. Chem. Res. 46(11): 2407-2415. Doi: 10.1021/ar300327a

20. Canton R, Gonzalez-Alba JM and Galan JC. CTX-M enzymes: origin and diffusion. Front Microbiol. 2012; 3: 110. Doi: 10.3389/ fmicb.2012.00110

21. Ferjani S, Saidani M, Ennigrou S, Hsairi M, Slim AF and Boubaker IB. Multidrug resistance and high virulence genotype in uropathogenic Escherichia coli due to diffusion of ST131 clonal group producing CTX-M-15: an emerging problem in a Tunisian hospital. Folia Microbiol (Praha). 2014; 59(3): 257-262. Doi: 10.1007/s12223-013-02920.

22. Frost LS, Leplae R, Summers AO and Toussaint A. Mobile genetic elements: the agents of open source evolution. Nat Rev Microbiol. 2005; 3(9): 722-732. DOI:10.1038/nrmicro1235.

23. Johnson TJ and Nolan LK. Pathogenomics of the virulence plasmids of Escherichia coli. Microbiol Mol Biol Rev.2009; 73 (4): 750-774. Doi:10.1128/MMBR.00015-09.

24. Clinical and Laboratory Standards Institute. Development of in vitro susceptibility testing criteria and quality control parameters for veterinary antimicrobials agents; approved guidelines-second edition. Document M37-A2. Wayne, PA: CLSI, 2002. 